\title{
Stress-Dependent Matrix Cracking in 2D Woven SiC-fiber Reinforced Melt-Infiltrated SiC Matrix Composites
}

\author{
Gregory N. Morscher ${ }^{*}$ \\ Ohio Aerospace Institute \\ Brookpark, $\mathrm{OH}$
}

\section{ABSTRACT}

The matrix cracking of a variety of SiC/SiC composites has been characterized for a wide range of constituent variation. These composites were fabricated by the 2-dimensional lay-up of $0 / 90$ five-harness satin fabric consisting of Sylramic fiber tows that were then chemical vapor infiltrated (CVI) with BN, CVI with SiC, slurry infiltrated with SiC particles followed by molten infiltration of $\mathrm{Si}$. The composites varied in number of plies, the number of tows per length, thickness, and the size of the tows. This resulted in composites with a fiber volume fraction in the loading direction that ranged from 0.12 to 0.20 . Matrix cracking was monitored with modal acoustic emission in order to estimate the stress-dependent distribution of matrix cracks. It was found that the general matrix crack properties of this system could be fairly well characterized by assuming that no matrix cracks originated in the load-bearing fiber, interphase, chemical vapor infiltrated SiC tow-minicomposites, i.e., all matrix cracks originate in the $90^{\circ}$ tow-minicomposites or the large unreinforced SiC-Si matrix regions. Also, it was determined that the larger tow size composites had a much narrower stress range for matrix cracking compared to the standard tow size composites.

\section{INTRODUCTION}

SiC-fiber reinforced, melt-infiltrated (MI) SiC matrix composites are leading candidate materials for aircraft and land-based turbine engine

\footnotetext{
- Senior Research Scientist residing at NASA Glenn Research, Cleveland, $\mathrm{OH}$
} 
applications such as a combustor liner [1-2]. However, for such materials to be used, the stress-strain behavior of these materials needs to be well characterized for composites with a wide range of physical characteristics, e.g., thickness, fiber architecture, fiber volume fraction, etc... since composite structures are not necessarily simple shapes but consist of thickness changes, curvature, and attachment schemes depending on the need of the component. In order to model the stress-response of these materials a good understanding of their matrix crack properties are required since matrix cracking, as a result of fiber debonding and sliding in and around the "plane" of a matrix crack, results in the desired stress-strain non-linearity, composite toughness, and strength properties [3]. For non-oxide composites, such as the SiC/SiC system, the presence of matrix cracks enables oxidizing environments to diffuse into the interior of the composite and cause strength-degradation, especially at intermediate temperatures [4-5]. In addition, for some BN interphase composites, the degree of strength-degradation at intermediate temperatures is related to the number of matrix cracks [6]. Therefore, it is essential that a good understanding of the stress-dependent matrix crack properties of a viable composite system be wellcharacterized. For example, this has been done to a large extent for the Nicalon $^{\text {TM\# }}$, C interphase, CVI SiC matrix system [7-8].

A considerable amount of composite development has occurred for the $\mathrm{SiC}$ fiber-reinforced, BN interphase, MI matrix system [9-11]. This development has included studying different fiber-types, interphases, and matrix compositions in order to maximize composite properties. Most of the development composite panels have been processed with the Sylramic ${ }^{*}$ or the newer Sylramic-iBN fibertype. The latter offers the strongest, most creep-resistant, and most reliable composites to date. A variety of composite specimens were tested in this study from those developmental panels with a wide variation of the 2D woven, five-

\footnotetext{
* Nippon Carbon Co., Tokyo, Japan

* Dow Corning Corporation, Midland MI
} 
harness satin (5HS) architecture, e.g., changes in composite thickness, number of plies, number of tows per length, and the number of fibers per tow. An earlier work [12] compared the effects of these changes on the stress-strain curve in general. This study will concentrate on characterizing the effect these changes have on matrix cracking towards the development of a general relationship that can be used for purposes of component design and performance modeling.

\section{EXPERIMENTAL}

Unload-reload tensile hysteresis tests were performed on ten different composite specimens, each from a different SiC/SiC composite panel, that varied in fiber tow ends per unit length, number of plies, and composite thickness. Two different fiber-types were used, Sylramic (Syl) and insitu-BN Sylramic (Syl-iBN) which is a modified Sylramic fiber that has been heat-treated [11] to form an insitu $\mathrm{BN}$ layer ( $\mathrm{B} \mathrm{BN}$ ) on the fiber surface prior to composite fabrication. However, the differences in the fiber-types are considered to not affect matrix-cracking behavior. For one composite panel, 041, a double-tow was woven at 10 ends per inch (epi) instead of a single-tow weave of 20 epi [13]. The composites were processed by the former Honeywell Advanced Composites (Newark, DE.), currently known as General Electric Power Systems Composites [2]. Table I lists the constituent variations for the composites tested.

Composite processing entails first stacking of balanced $0 / 90$ five-harness fabric woven from SYL or SYL-iBN tows, a BN interphase layer deposition ( 0.5 $\mu \mathrm{m}$ ) via chemical vapor infiltration (CVI), a SiC interphase over-coating via CVI, SiC particulate infiltration via slurry-infiltration, and finally, liquid Si infiltration [12].

The tensile tests were performed on specimens with a contoured gage section (dog-bone) using a universal-testing machine (Instron Model 8562, Instron, Ltd, Canton Mass.) with an electromechanical actuator. Glass fiber reinforced epoxy tabs were mounted on both sides of the specimen in the grip regions and the specimens were gripped with rigidly mounted hydraulically 
actuated wedge grips. A clip-on strain gage, with a range of $2.5 \%$ strain over $25.4 \mathrm{~mm}$ gage length was used to measure the deformation of the gage section.

Modal acoustic emission ( $\mathrm{AE}$ ) was monitored during the tensile tests with two wide-band, $50 \mathrm{kHz}$ to $2.0 \mathrm{MHz}$, high fidelity sensors placed just outside the tapered region of the dog-bone specimen. Vacuum grease was used as a couplant and mechanical clips were used to mount the sensors to the specimen. The AE waveforms were recorded and digitized using a 4-channel, Fracture Wave Detector (FWD) produced by Digital Wave Corporation (Englewood, CO). The load and strain were also recorded. After the tensile test, the AE data was filtered using the location software from the FWD manufacturer in order to separate out the $A E$ that occurred outside of the gage section. For more information on the $\mathrm{AE}$ procedure and analysis, see references 14 and 15.

Since residual compressive stresses in the matrix close the matrix cracks, to measure crack density, sections of the tested tensile specimens in the gage section at least $10 \mathrm{~mm}$ long were polished and then plasma $\left(\mathrm{CF}_{4}\right)$ etched at 500 $W$ for 30 minutes. The etchant reacts with the free $S i$ in the matrix, removing much of it, making it impossible to observe cracks in the MI part of the matrix. Matrix cracks can only be observed in the dense CVI SiC layer between the BN and the MI matrix.

\section{RESULTS AND ANALYSIS}

\section{Standard Single Tow Woven Composites}

A monotonic and an unload-reload stress strain data with AE activity plotted as energy are shown in Figure 1. Several aspects of Figure 1 are characteristic of the Sylramic/BN/MI SiC system. For specimens from the same panel of material, the stress-strain properties are fairly consistent for monotonic and unload-reload experiments. Also, the AE activity is very consistent and occurs over a range of stress (strain). Finally, the matrix is in residual compression, which is indicative of the intersection of the intercepts of the 
average slope of the top portion of the hysteresis loop in the positive stressstrain quadrant, according to Steen [16].

Figure 2 shows stress-strain curves, unload-reload loops removed, for a variety of different architecture composites. As is expected, the higher volume fraction composites tend to exhibit higher ultimate strengths, higher stresses for the "knee" in the stress-strain curve, and steeper secondary slopes [12]. There was considerable scatter in elastic moduli, some of which was due to the anomalies described below.

The matrix crack density was determined for a number of specimens after tensile testing. Figure 3 shows an example of matrix cracking in these composites for a portion of a specimen cut and polished from the gage section followed by a plasma-etch. No matrix cracks are visible, because of the residual compression in the matrix and the higher interfacial shear stresses of composites with Sylramic fibers, without plasma etching.

The energy of AE has shown to be a good measure of the relative crack density when the more accurate "modal" AE approach is used for these types of composite systems [15]. In other words, the relative amount of cumulative $A E$ energy is directly related to the relative number of matrix cracks formed. Therefore, the final matrix crack density measured from the composite test specimens was multiplied by the normalized cumulative AE energy (Figure 1b) for each specimen in order to estimate the stress-dependent matrix crack distribution. The estimated crack distributions are shown in Figure 4 for a number of specimens. There is considerable scatter in the data, which will be discussed below, but in general, the stress-dependent crack density distribution occurs over a higher stress range for higher fiber volume fraction composites.

Even though the composite panels were fabricated by the same vendor over a relatively short period of time, $\sim 1$ year, there were several anomalies observed for the composites tested in this study:

(1) Two types of interfacial debonding and sliding behaviors were present in the data set for this study and noted in Table I. Most of the specimens 
exhibited debonding between the fiber and the $\mathrm{BN}$-interphase, this was referred to as "inside debonding" (ID). Two specimens exhibited debonding between the BN-interphase and the CVI SiC portion of the matrix, this was referred to "outside debonding" (OD). Also, two specimens exhibited a mixture of inside and outside debonding, i.e., "mixed debonding" (MD). This was pointed out in reference 12 and has been described in greater detail in a recent paper [17]. OD composites have much lower interfacial shear stresses, $\sim 10 \mathrm{MPa}$, compared to the $70 \pm 10$ MPa measured for ID composites. Also, OD composites typically had lower elastic modulus values, $\sim 220 \mathrm{MPa}$, compared to the $250 \pm 30 \mathrm{MPa}$ measured for ID composites. Note that the two composites with the higher stress-distributions for matrix cracking were OD (044) and MD (011) specimens.

(2) The matrix crack density varied from $5 \mathrm{cracks} / \mathrm{mm}$ to $12 \mathrm{cracks} / \mathrm{mm}$ and did not appear to show any correspondence with the fiber volume fraction or interfacial shear strength (Table I).

(3) Many of the composites did not fully saturate with matrix cracks. This was especially true for those composites with lower fiber volume fractions as indicated by the high rate of AE activity at failure (Figure 4).

\section{Normalizing Matrix Cracking Behavior for Standard Single Tow Woven}

\section{Composites}

It is evident that there is some relationship between fiber volume fraction and matrix cracking and it would be useful to characterize matrix cracking based on the constituent properties of the composites and the matrix in particular. Matrix cracks originate within the $90^{\circ}$ tow-minicomposites or large, unreinforced matrix regions and then propagate through the load-bearing minicomposites [18]. In other words, matrix cracks do not originate for these materials in the load-bearing fiber, interphase, CVI SiC "tow-minicomposite". If the volume fraction and elastic modulus of an average "minicomposite" can be determined 
from the processing data, then the average stress in the matrix region excluding the BN and CVI SiC in the load-bearing minicomposite could be backed out from a rule-of-mixtures approach and a relationship between matrix cracking and matrix stress can be established.

The fraction of load-bearing minicomposites, $f_{\text {mini, }}$ was estimated from half of the combined fraction of fiber, BN, and CVI SiC determined from the processing data sheet supplied by the composite fabricator* The elastic modulus of the minicomposites, $E_{\text {mini, }}$ was estimated via the rule-of-mixtures from the elastic moduli of each constituent of the minicomposite $\left(E_{f}=380 \mathrm{GPa}, E_{B N}=60 \mathrm{GPa}\right.$, and $E_{\text {CVI-Sic }}=425 \mathrm{GPa}$ ) and the fraction of each constituent in the loading direction. Again, a rule-of-mixtures approach can be used to "back-out" the stress in the "minimatrix" surrounding the load-bearing minicomposites based on processing data for each composite panel:

$$
\sigma_{\text {minimatrix }}=\frac{\left(\sigma_{c}+\sigma_{t h}\right)}{E_{c}}\left(\frac{E_{c}-f_{\min i} E_{\min i}}{1-f_{\min i}}\right)
$$

where, $\sigma_{c}$ is the composite stress, $\sigma_{\text {th }}$ is the residual compressive stress in the matrix [19] which was found to be higher, in general, for higher volume fraction composites with inside debonding [12], and $\mathrm{E}_{c}$ is the measured composite elastic modulus from the $\sigma / \varepsilon$ curve.

Figure 5 shows the estimated stress-dependent matrix crack distribution versus $\sigma_{\text {minimatrix. }}$ There is considerable convergence of the matrix crack data with this normalization step even though there is a wide scatter in $E$ and the differences in debonding and sliding character, i.e., interfacial shear stress. However, for specimens with the fewer number of plies, the matrix crack distribution appears to be broader in $\sigma$ and $\sigma_{\text {minimatrix, }}$ but still within the range of

\footnotetext{
* The raw data from the manufacturer is based on weight gains after each processing step. The $f_{\text {mini }}$ and $\sigma_{\text {mini }}$ determined from the processing data are tabulated in Table I.
} 
matrix cracking exhibited by the standard eight ply panels. Also, there appears to be a small separation in $\sigma_{\text {minimatrix }} \sim 10 \mathrm{MPa}$, between the lowest (12.5) epi composites and those woven with higher (18 to 22 ) epi. The matrix crack distribution for the lower epi composites occurring at lower $\sigma_{\text {minimatrix }}$ range but with about the same relative slopes as higher volume fraction composites. This perhaps does indicate an effect of architecture on the nature of matrix cracking in these composites; however, for the use of these materials in actual components, composite architectures will most likely use the higher epi ranges and higher fiber fractions where the behavior was fairly consistent.

Other attempts were made to relate the crack-distributions as well. The data was compared only using the volume fraction of fibers in the loading direction, $f_{0}$, and $E_{f}$ in equation 1 instead of $f_{\operatorname{mini}}$ and $E_{\operatorname{mini}}$, respectively. The data was compared without the use of a residual stress term in equation 1. Finally, the data was compared using only $f_{o}$ and no residual stress term. None of these attempts resulted in the convergence of the data as well as the "minimatrix" approach.

\section{Matrix Cracking in Double-Tow Woven Composites}

The estimated crack density versus composite stress and $\sigma_{\text {minimatrix }}$ for the composite specimen woven with a double-tow (specimen 041 in Table I) are also shown in Figures 4 and 5, respectively. Matrix cracking occurs over a significantly narrower stress-range for the double-tow woven composites compared to the standard single-tow woven composites and at lower stresses when comparing similar volume fraction composites (Figure 4). This also is evident in the $\sigma_{\text {minimatrix }}$ range of matrix cracking where the matrix cracking in the double-tow composites occurs at significantly lower stresses.

\section{DISCUSSION}

To model the stress-strain response of ceramic matrix composites, knowledge of the stress-dependent number of matrix cracks is essential [18-21]. 
Usually this can only be determined experimentally for the composite system studied. Although, Curtin et al. [19] have proposed a matrix cracking model based on the distribution of flaws in the matrix, the distribution of matrix cracks that emanate from some of those flaws, and the interaction of neighboring matrix cracks that ultimately leads to matrix crack saturation when the fiber sliding lengths extend the length of the uncracked matrix segments. An attempt was made to model the matrix crack distribution according to the Weibull model put forward by Curtin et al. [19]; however, it was not very robust for the variety of composites studied here.

It is evident from the analysis in this study that the stress-dependence for matrix cracking in the Sylramic/BN/MI SiC composite system can be well characterized by a simple rule-of-mixtures relationship (Equation 1) up to about half the saturation crack density, $\sim 5 \mathrm{cracks} / \mathrm{mm}$. For higher fiber volume fraction composites, this relates to stresses in excess of $250 \mathrm{MPa}$, much higher than their expected use conditions for long-time combustor applications [2]. Only a few properties of the composite were required to formulate this relationship: the undamaged elastic modulus, Ec, the residual stress in the matrix, $\sigma_{\text {th }}$ and the properties of the load-bearing minicomposite, $E_{\text {minimatrix }}$ and $\sigma_{\text {minimatrix. }}$ The former two properties were found from a simple load-unload tensile test at room temperature and the later two properties were estimated from the composite processing data. If one fabricated a component out of this material, all they would require would be to fabricate a few "witness" panels of varying architecture to determine the needed composite properties and verify this stressdependent matrix cracking relationship. It would also be possible to determine EC from acoustic techniques and estimate $\sigma_{\text {th }}$. However, testing witness panels would give one insight as to the interfacial debonding and sliding properties which could be estimated from the stress-strain curve and stress-dependent matrix crack distribution and would be necessary for modeling the stress-strain behavior [12]. 
The understanding of the stress-dependent matrix cracking behavior can now be used to model the stress-strain curve [12] for a range of 2D woven architectures, number of plies, and composite thickness. For example, the stressdependent matrix crack distribution for the higher epi composites ( $>16$ epi) was fit with a simple linear relationship for $\sigma_{\text {minimatrix }}$ above $95 \mathrm{MPa}$ (Figure 5):

$$
\rho_{c}=0.1034 \sigma_{\text {minimatrix }}-9.8074
$$

where $\rho_{c}$ is the stress-dependent matrix crack density. This data was then used to model the $\sigma / \varepsilon$ curve over the appropriate stress range for two specimens (012 and 068 ) with similar interfacial shear stress, $\tau$, of $\sim 70 \mathrm{MPa}$ (Figure 6 ) from the approach taken in reference 12 based on references 19 and 20:

$$
\varepsilon=\sigma / E_{c}+\alpha \delta(\sigma) \rho_{d} / E_{f}\left(\sigma+\sigma_{t h}\right) ; \quad \text { for } \rho_{c}^{-1}>2 \delta
$$

where the sliding length

$$
\delta=\alpha r\left(\sigma+\sigma_{\text {th }}\right) / 2 \tau
$$

$r$ is the fiber radius, and

$$
\alpha=(1-f) E_{m} / f E_{c}
$$

The stress-dependent matrix cracking behavior at room temperature can be used to model the time-dependent elevated temperature life expectancy at stress [6]. The stress-strain curve of these composites upon initial loading varies only slightly up to $1200^{\circ} \mathrm{C}$ [2]. Little difference is observed in load-unload behavior at $815^{\circ} \mathrm{C}$, including $\sigma_{\mathrm{th}}$, until higher stresses are reached ( $>275 \mathrm{MPa}$ ) after considerable exposure time ( $\sim 30$ minutes) in air at temperature during the unload-reload test. Therefore, it can be assumed that the matrix cracking of 
these materials upon initial loading behaves essentially the same as at room temperature and the stress-dependent matrix-crack distribution can be used as the initial crack density at elevated temperatures upon loading. Evidence of this has been demonstrated on a number of different panels which have been subjected to stress-rupture testing at $815^{\circ} \mathrm{C}$ where the measured crack densities after rupture are commensurate with what would have been expected from the AE data and known final crack density measured after room temperature testing to failure (Figure 7). After rupture, cracks remain open due to the formation of solid oxidation products in the matrix crack and there is no need to etch the polished sections. It should be noted that for the Sylramic/BN/MI system, it has been shown that relatively little global AE activity occurs after initial loading for stress-rupture tests at $815^{\circ} \mathrm{C}$ [22], i.e., little matrix crack formation or growth occurs after loading.

The differences between the double-tow woven and single tow woven matrix cracking behaviors were striking. The double-tow woven composites have shown higher composite strengths for the same volume fraction composites [15]. However, the relatively lower stress range for matrix cracking may be detrimental for use of these composites at higher stresses due to strengthdegrading oxidation processes. The much narrower matrix crack distribution for the double-tow composites approaches the more classical assumption of a single matrix crack stress [3]. The narrow matrix cracking stress range must either be due to the larger tow size or a different matrix flaw distribution, presumably, from larger $90^{\circ}$ tows and larger unbridged matrix region. In recent tests performed on 3D architecture composites with double-tows in the load-bearing direction and single-tows perpendicular to the loading-direction, almost the identical narrow stress-range versus $\sigma_{\text {minimatrix }}$ was found to exist; however, it occurred at lower stresses [23]. This implies that the narrow stress range for matrix cracking is due to the large tow size in the loading-direction because only single-tows were used in the $90^{\circ}$ direction for these 3D composites. However, 
the absolute stress-range for matrix cracking was dependent on the type of woven architecture and concentration of composite constituents.

Finally, it should be noted that the specific results of this study only apply to the Sylramic/BN/MI properties from this vendor. Changing the fiber, interphase, matrix, or possibly even the vendor could alter the absolute nature of matrix cracking of that composite system compared to what was found in this study. However, the methodology and approach taken here would be expected to be applicable for a different composite system as a way to characterize the stress-dependent crack distribution.

\section{CONCLUSIONS}

A relationship for matrix cracking versus applied stress was effectively established by assuming that matrix cracks originate in the region of the material outside of the load-bearing minicomposite for the 2D woven Sylramic fiber, BN interphase, melt-infiltrated $\mathrm{SiC}$ matrix composite system. This was confirmed for a number of composite specimens processed with different fiber architectures and numbers of plies resulting in varied concentrations of composite constituents. A simple mathematical relationship for stress-dependent matrix cracking was used to describe the stress-dependent matrix crack density from which the stress-strain response for a composite component for areas of different thickness, numbers of plies, and/or 2D fiber architectures could be modeled. The stress-dependent matrix crack distribution also provides the starting crack density for modeling the elevated temperature properties of these composites when subjected to mechanical loads at temperature.

\section{ACKNOWLEDGEMENT}

This work was supported by the Ultra Efficient Engine Technology (UEET) program at NASA Glenn Research Center. The author also appreciated the suggestion by Dr. William Curtin of Brown University to assume matrix cracking occurs outside the load-bearing minicomposite. 


\section{REFERENCES:}

1. A.M. Johnson, B.J. Bartlett, and W.A. Troha, Thirteenth International Symposium for Air Breathing Engines, ISABE 97-7179, F.S. Billig ed., Vol. 2 (1997) pp. 1321-1328

2. D. Brewer, Mater. Sci. Eng. A, Vol. A261 (1999) pp. 284-291.

3. J. Aveston, G.A. Cooper, and A. Kelly, in The Properties of Fibre Composites, Conference Proceedings. National Physics Laboratory (Guilford, U.K.) IPC Science and Technology Press, Ltd. Teddington, U.K., 1971, pp. 15-24.

4. F.E. Heredia, J.C. McNulty, F.W. Zok, and A.G. Evans, J. Amer. Ceram. Soc., Vol. 79, No. 5 (1996) pp. 1181-88

5. G.N. Morscher, J. Hurst, and D. Brewer, J. Am. Ceram. Soc., 83 [6] 144149 (2000)

6. G.N. Morscher and J.D. Cawley, J. European Ceramic Society, vol. 22, no. 14-15, pp. 2777-2788 (2002)

7. P. Pluvinage, A. Parvizi-Majidi, and T.W. Chou, J. Mater. Sci., Vol. 31 (1996) 232-241

8. L. Guillaumat and J. Lamon, "Multi-fissuration de composites $\mathrm{SiC} / \mathrm{SiC}$," Revue des composites et des materiaux avances. Vol 3., pp. 159-171 (1993)

9. J. A. DiCarlo, H.M. Yun, G.N. Morscher, and L.U. Thomas-Ogbuji, in High Temperature Ceramic Matrix Composites, W. Krenkel, R. Naslain, and H. Schneider, Eds. Wiley-VCH, Weinheim, Germany, 2001 pp. 777-782

10. H.M. Yun and J. A. DiCarlo, in High Temperature Ceramic Matrix Composites, W. Krenkel, R. Naslain, and H. Schneider, Eds. Wiley-VCH, Weinheim, Germany, 2001 pp. 99-105

11.H.M. Yun, J.Z. Gyekenyesi, Y.L. Chen, D.R. Wheeler, and J.A. DiCarlo, Ceram. Eng. Sci. Proc., Vol. 22, No. 3, (2001) 521-531. 
12. G.N. Morscher and J.I. Eldridge, Advances in Fracture Research Proceedings of International Conference of Fracture 10 on compact disk, Honolulu 2001 (Elsevier Science) eds. Ravi-Chandar et al.

13. Yun and DiCarlo, unpublished data.

14. G.N. Morscher, Comp. Sci. Tech., Vol. 59, No. 5 (1999) pp. 687-697. 15. G.N. Morscher, Review of Progress in Quantitative Nondestructive Evaluation, Vol. 18A, D.O. Thompson and D.E. Chimenti, Eds., Kluwer Academic/Plenum Publishers, NY, 1999, pp. 419-426.

16. M. Steen and J.L. Valles, ASTM STP 1309, M.G. Jenkins et al., Eds. American Society for Testing and Materials, West Conshohocken, PA, 1997, pp. 49-65

17. G.N. Morscher, H.M. Yun, and J.A. DiCarlo, J. Amer. Ceram. Soc. In print. 18. J.M. Domergue, F.E. Heredia, and A.G. Evans, J. Amer. Ceram. Soc., Vol. 79, No. 1, (1996) pp. 161-170

19.W.A. Curtin, B.K. Ahn, and N. Takeda, Acta mater., Vol. 46, No. 10, (1998) pp. 3409-3420.

20.A.W. Pryce and P.A. Smith, Br. Ceram. Trans., Vol. 92, No. 2 (1993) 4954.

21. N. Lissart and J. Lamon, Acta mater., Vol 45., No. 3, (1997) 1025-1044

22. G.N. Morscher and J. Hurst, Ceram. Eng. Sci. Proc., 22 [3] 547-552 (2001)

23. G.N. Morscher, H.M. Yun, and J. DiCarlo, submitted to Comp. Sci. Tech. 
TABLE 1: Properties of tested SiC/SiC specimens

\begin{tabular}{|c|c|c|c|c|c|c|c|c|c|c|}
\hline $\begin{array}{c}\text { Specimen } \\
\text { (type of } \\
\text { debonding*) }\end{array}$ & $\begin{array}{c}\text { Sylramic } \\
\text { Fiber } \\
\text { Type** }\end{array}$ & $\begin{array}{c}\text { Tow } \\
\text { Ends } \\
\text { per } \\
\text { Inch }\end{array}$ & $\begin{array}{c}\text { No. } \\
\text { of } \\
\text { Plies }\end{array}$ & \begin{tabular}{|c|} 
Composite \\
Thickness, \\
mm
\end{tabular} & $\begin{array}{c}\text { Crack } \\
\text { density at } \\
\text { composite } \\
\text { failure, } \\
\# / \mathbf{m m}\end{array}$ & $f_{0}$ & $\begin{array}{c}E_{r} \\
\text { GPa }\end{array}$ & $\begin{array}{l}\sigma_{\text {thr }} \\
\mathrm{MPa}\end{array}$ & $\mathbf{f}_{\operatorname{mini}}$ & $E_{\operatorname{mini}}$ \\
\hline \multicolumn{11}{|c|}{ Single tow woven composites } \\
\hline $007(\mathrm{OD})$ & $\mathrm{AP}$ & 12.5 & 8 & 1.63 & 8.0 & 0.15 & 219 & -35 & 0.30 & 357 \\
\hline 016 (ID) & iBN & 12.5 & 8 & 2.04 & 11.6 & 0.12 & 279 & -35 & 0.38 & 386 \\
\hline 017 (ID) & $\mathrm{iBN}$ & 12.5 & 8 & 1.46 & 12.0 & 0.17 & 224 & -53 & 0.35 & 366 \\
\hline 012 (ID) & $\mathrm{iBN}$ & 18 & 6 & 1.99 & 7.2 & 0.14 & 289 & -37 & 0.36 & 379 \\
\hline 009 (MD) & $\overline{A P}$ & 20 & 8 & 2.18 & 9.0 & 0.18 & 252 & -42 & 0.36 & 355 \\
\hline 011 (MD) & $\overline{i B N}$ & 20 & 8 & 2.04 & 10.3 & 0.19 & 228 & -57 & 0.34 & 361 \\
\hline 018 (ID) & $\mathrm{iBN}$ & 20 & 4 & 1.37 & 5.0 & 0.14 & 235 & -53 & 0.29 & 364 \\
\hline $044(O D)$ & iBN & 22 & 8 & 2.14 & 9.5 & 0.20 & 216 & -35 & 0.35 & 369 \\
\hline 068 (ID) & $\mathrm{iBN}$ & 22 & 8 & 2.21 & 10.4 & 0.20 & 277 & -63 & 0.39 & 366 \\
\hline \multicolumn{11}{|c|}{ Double tow woven composite } \\
\hline $041(O D)$ & iBN & $10(2)$ & 8 & 2.07 & & 0.19 & 197 & -50 & 0.33 & 363 \\
\hline
\end{tabular}



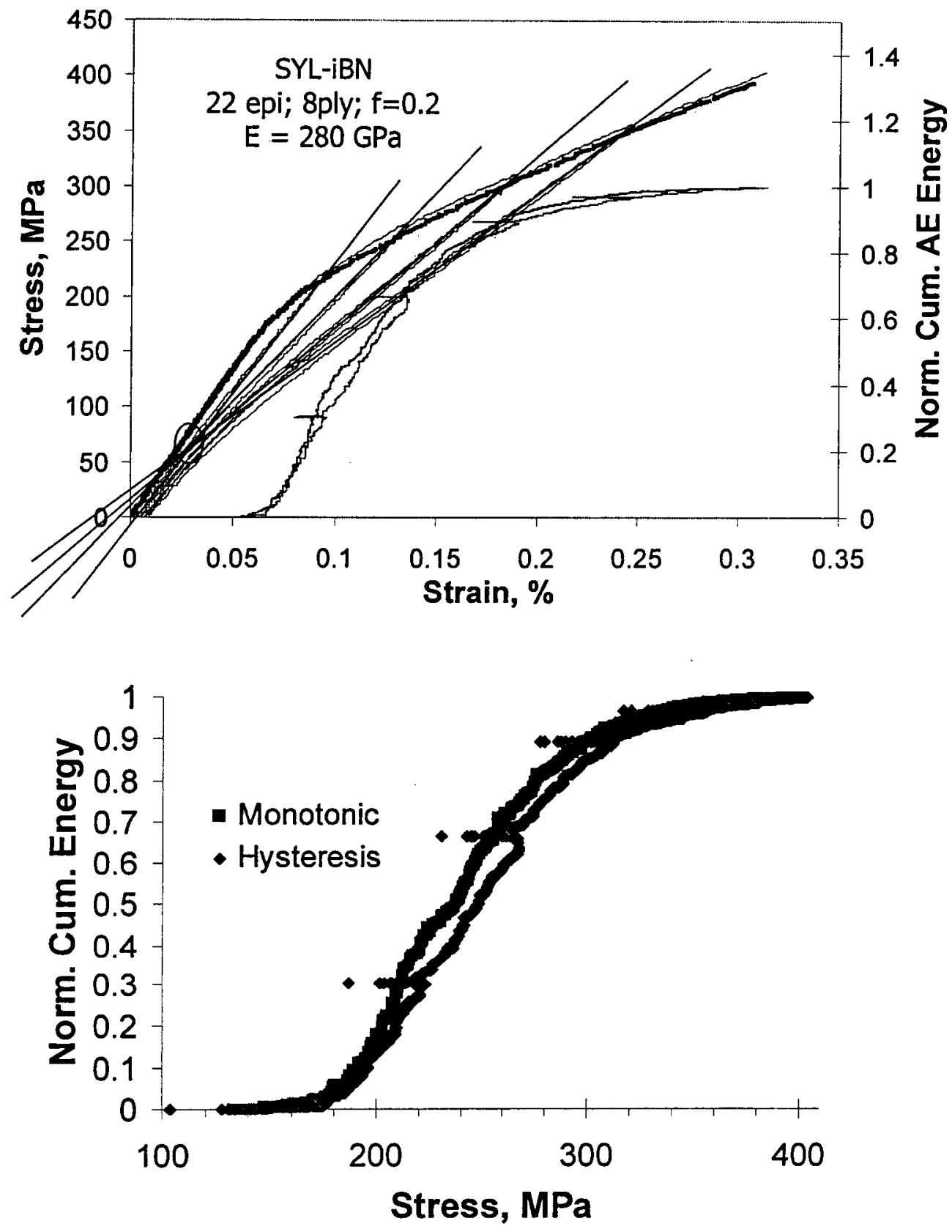

Figure 1: Typical (068) monotonic and load-unload-reload hysteresis (a) stressstrain behavior and (b) stress-dependent AE activity. 


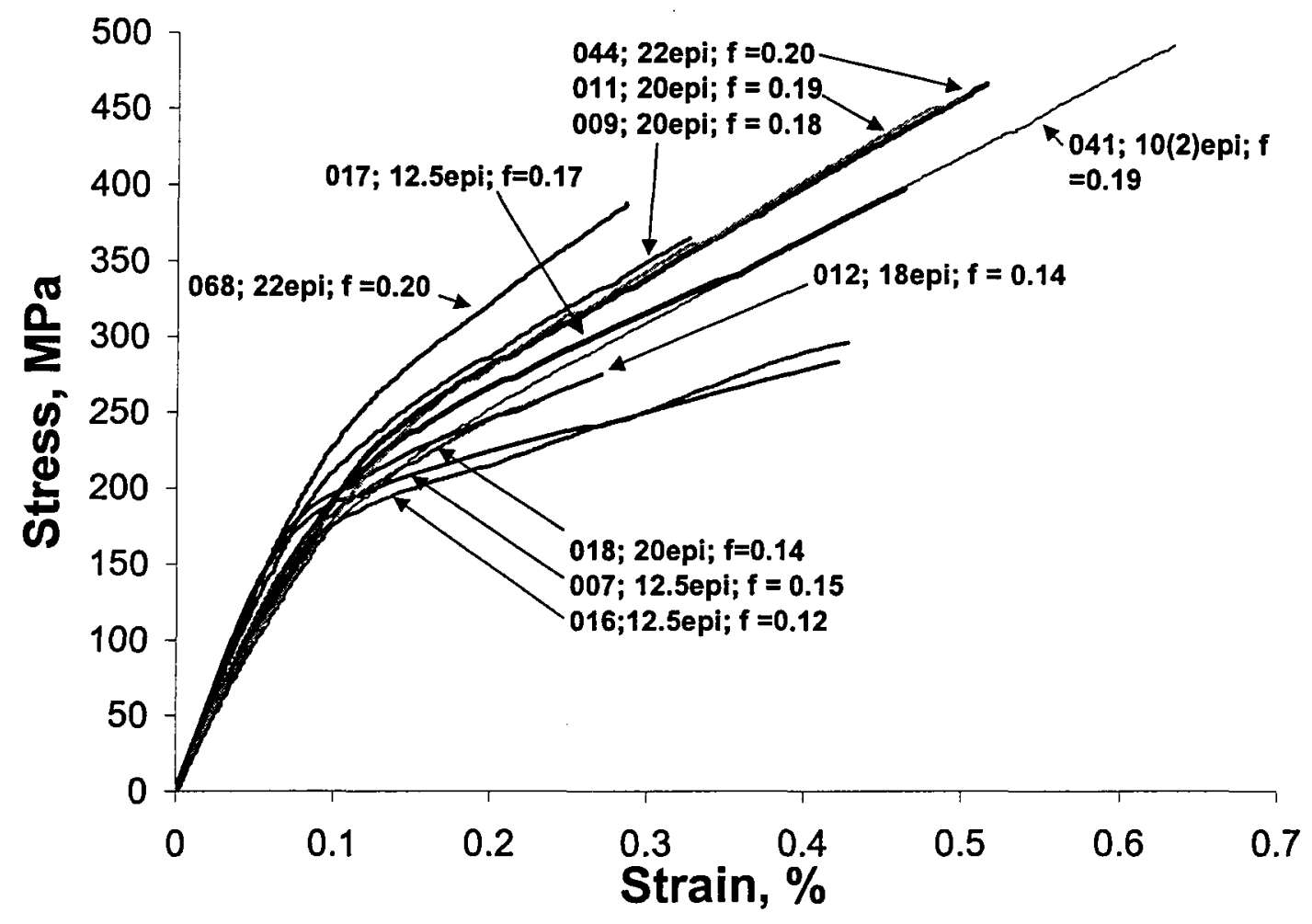

Figure 2: Stress-strain curves for the specimens tested and analyzed in this study. 


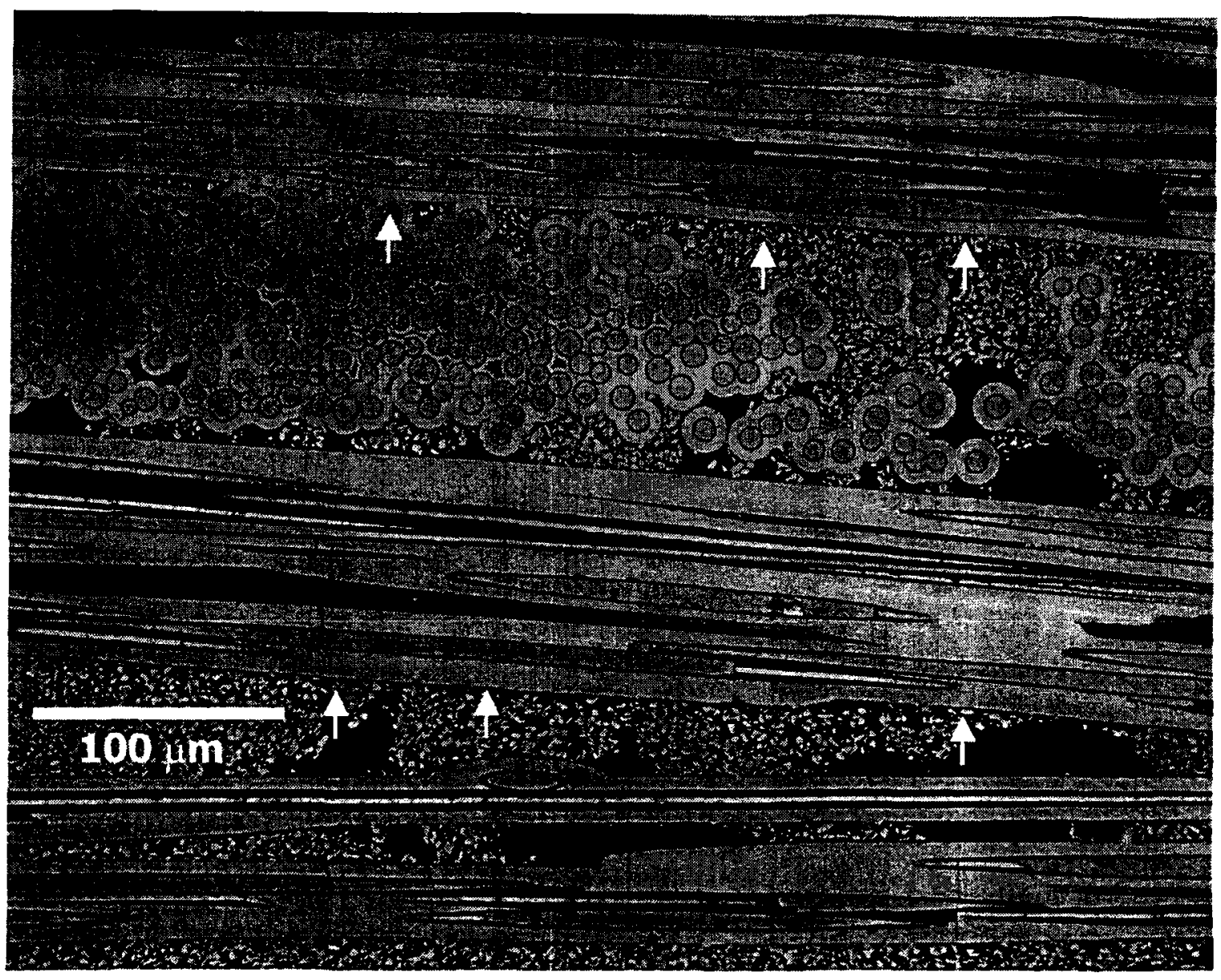

Figure 3: Example of matrix cracks observed along a polished and etched longitudinal section of the tensile specimen (017) after failure at room temperature. 


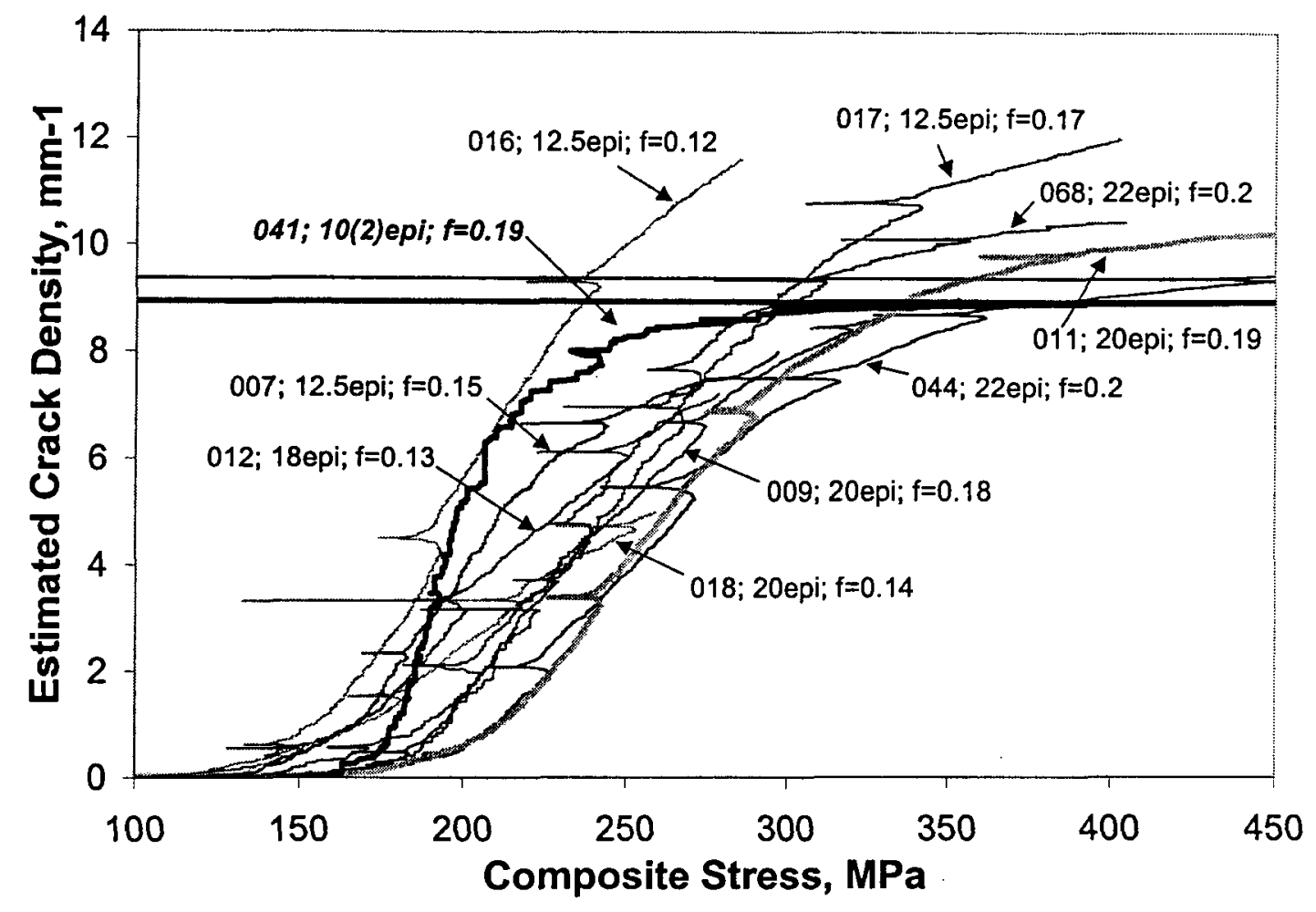

Figure 4: Stress-dependent matrix cracking based on the normalized AE measured during the stress-strain test for standard single tow woven composites and a double tow woven composite (041). 


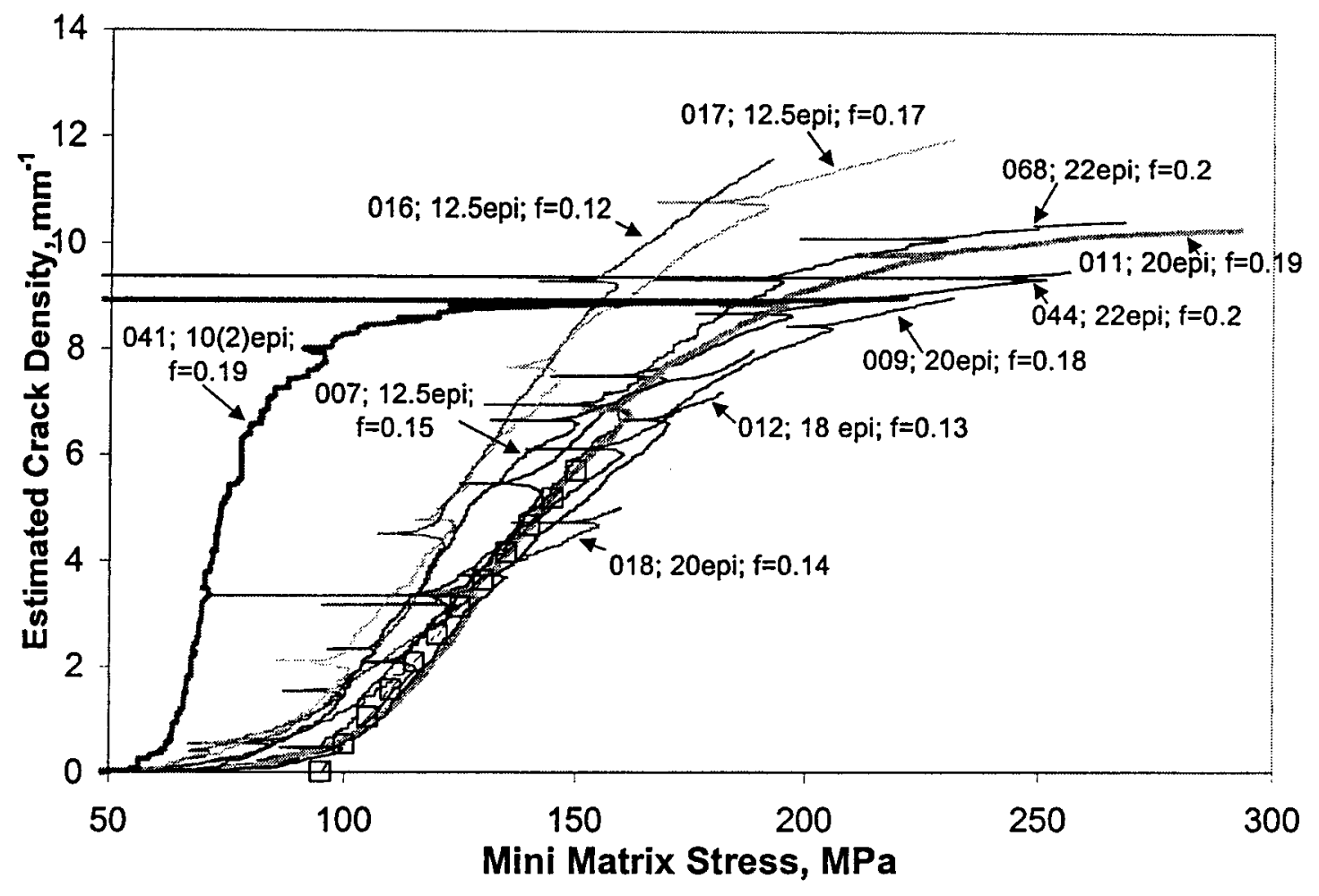

Figure 5: Stress-dependent matrix cracking versus $\sigma_{\text {minimatrix }}$ for standard single tow woven composites and a double tow woven composite (041). A simple bestfit of matrix crack density, up to $\sigma_{\text {minimatrix }}=150 \mathrm{MPa}$, for single tow woven composites with epi $\geq 16$ is plotted as open squares. 


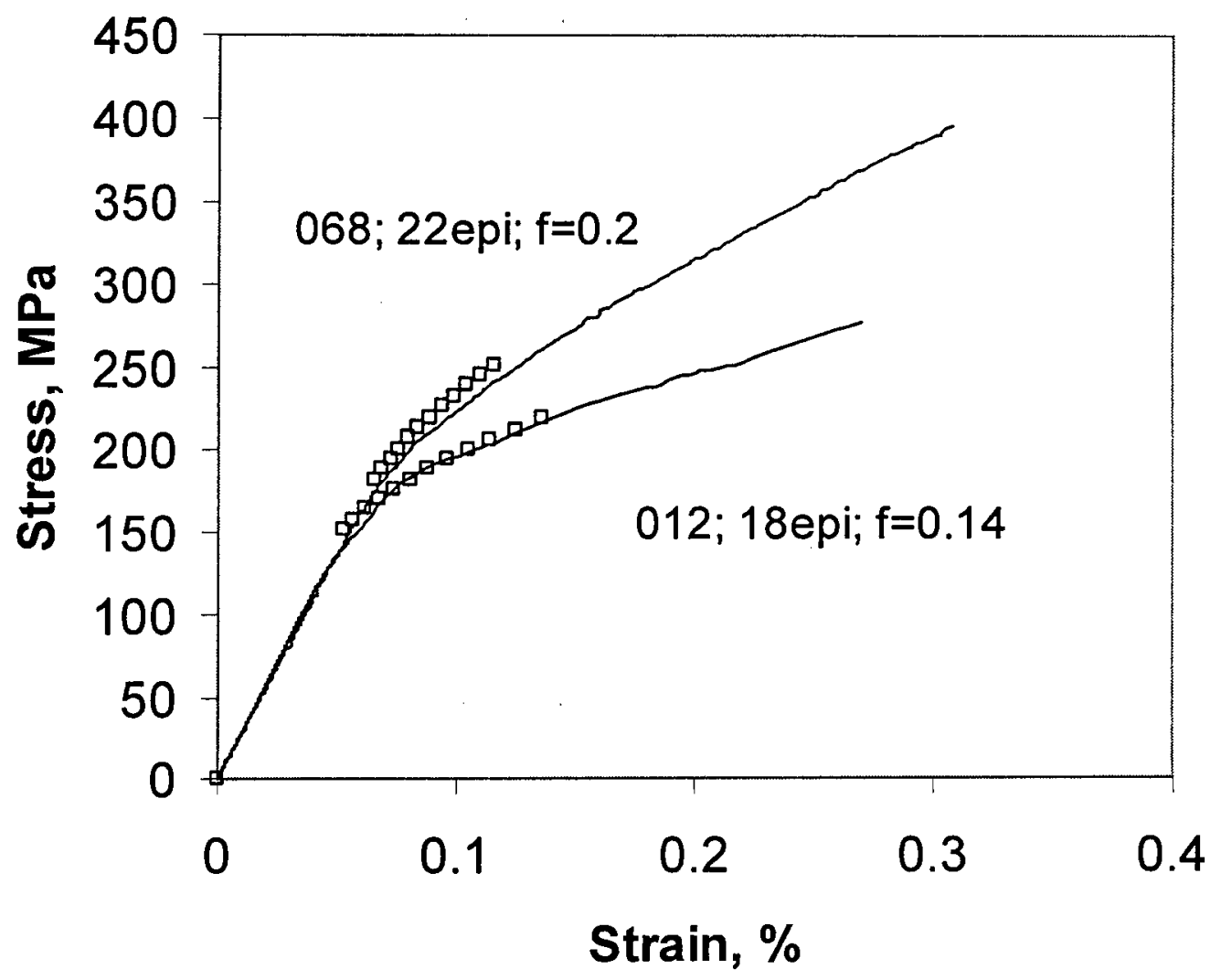

Figure 6: Stress-strain predictions based on best-fit matrix crack density for two different volume fraction composites with same $\tau=70 \mathrm{MPa}$. 


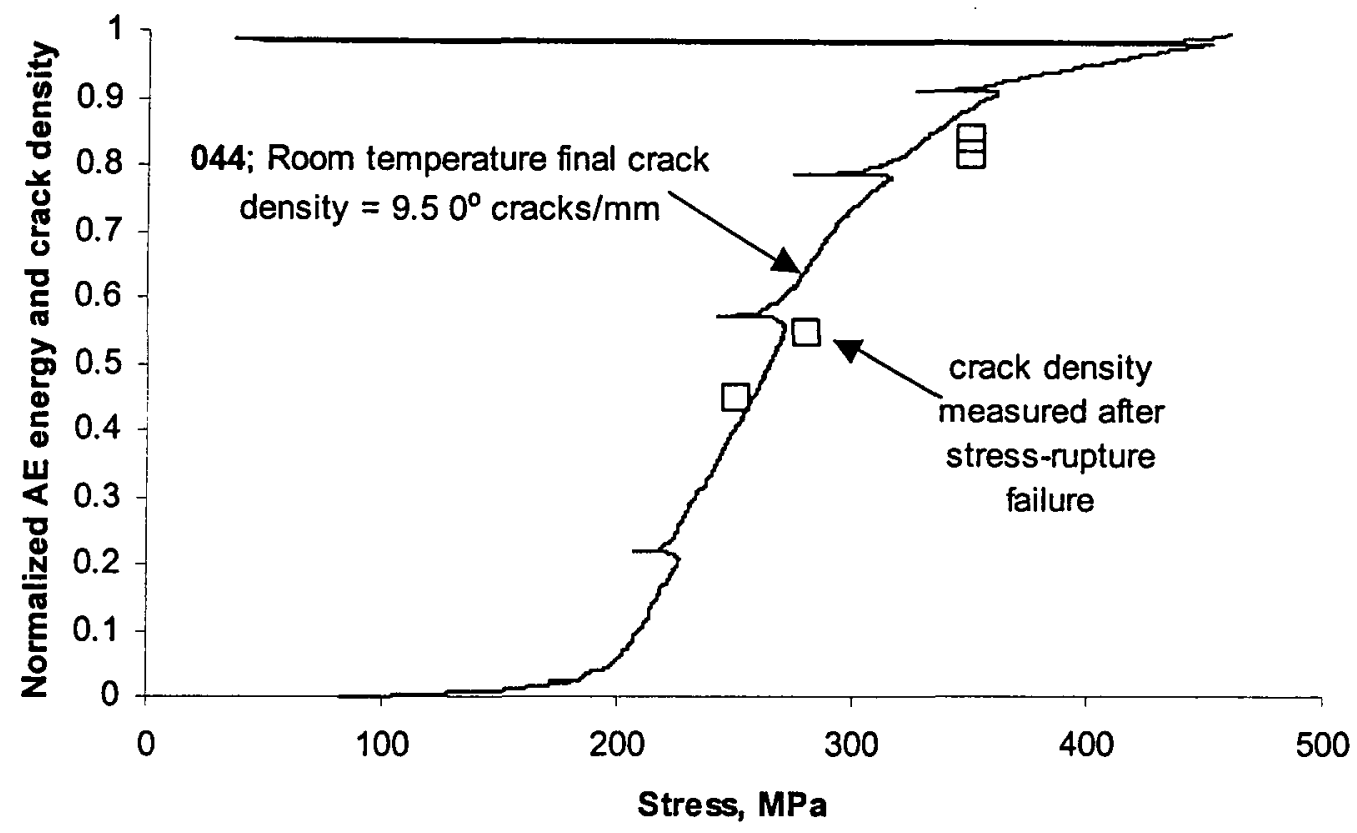

Figure 7: Crack density measured in the load-bearing minicomposites after stress-rupture at $815^{\circ} \mathrm{C}$ in air compared with the $\mathrm{AE}$ activity at room temperature for specimens from the same panel (044). 